\title{
Avaliação do Programa Institucional de Monitoria nos cursos de Hotelaria e Turismo da Universidade Federal de Pernambuco (Brasil), à luz do engajamento estudantil
}

\section{Evaluation of the Institutional Monitoring Program in the Hotel Management and Tourism courses in Federal University of Pernambuco (Brazil), from the student engagement view}

\author{
Maria Helena Cavalcanti da Silva Belchior (BELCHIOR, M. H. C. da S.) ${ }^{*}$; \\ Ana Rosa Cavalcanti da Silva (SILVA, A. R. C. da) ${ }^{\text {** }}$
}

\begin{abstract}
RESUMO - O cenário deste trabalho é focado em uma Universidade Pública Federal e no seu Programa Institucional de Monitoria. Tem como objetivo avaliar a monitoria acadêmica desenvolvida pelos estudantes dos cursos de Bacharelado em Hotelaria e em Turismo da Universidade Federal de Pernambuco (Brasil), no período de 2013.1 a 2018.1, a partir do engajamento de seus participantes. Classifica-se, quanto aos objetivos, a partir da perspectiva exploratória e explicativa. Possui uma abordagem qualitativa amparada nas análises de 17 relatórios de monitoria, em especial a seção avaliação de experiência da monitoria, relativas à participação dos discentes na condição de monitores. Para fins de tratamento dos dados optou-se pela criação de categorias, levando-se em consideração as dimensões do engajamento estudantil cognitiva, comportamental e emotiva. Como resultados, foi possível avaliar a permanência de um estudante continuadamente por três monitorias consecutivas sob orientação de um mesmo docente; em quatro dos relatórios todas as dimensões do engajamento foram encontradas. Ademais, a dimensão cognitiva foi a mais presente nos documentos analisados, 13 no total, o que, sobremaneira, aproxima o Programa Institucional de Monitoria ao engajamento estudantil com vistas a um aprendizado mais consistente e significativo do discente participante.
\end{abstract}

Palavras-chave: Turismo; Engajamento estudantil; Programa de monitoria; Experiência.

ABSTRACT - The scenario of this work is focused in a Federal Public University and its Institutional Monitoring Program. It aims to evaluate the academic monitoring developed by students of the Bachelor's courses in Hospitality and Tourism of the Federal University of Pernambuco (Brasil), from 2013.1 to 2018.1, based on the engagement of its participants. Related to the objectives it is classified with an

\footnotetext{
*Formação: Graduação em Turismo pela Universidade Federal de Pernambuco (UFPE). Mestrado em Gestão do Desenvolvimento Sustentável pela Universidade de Pernambuco. Doutoranda do Programa de Pós-Graduação em Educação Matemática e Tecnológica da Universidade Federal de Pernambuco (UFPE). Membro do Grupo de pesquisa Laboratório de Pesquisa e Prática - Educação, Metodologias e Tecnologias (EDUCAT). Atividade Profissional: Docente da Universidade Federal de Pernambuco, Departamento de Hotelaria e Turismo. Endereço físico para correspondência: Rua Tereza Melias s./n., Cidade Universitária. CEP: 50.670-901 - Recife/PE - Brasil. E-mail: mhcavalcanti@gmail.com

** Formação: Graduação em Comunicação Social (Jornalismo) pela Universidade Federal de Pernambuco (UFPE). Mestrado em Gestão do Desenvolvimento Sustentável pela Universidade de Pernambuco. Atividade Profissional: Docente do Centro Universitário UniFBV Wyden nos Cursos Superiores de Administração de Empresas e Gestão de Recursos Humanos. Endereço físico para correspondência: Rua Jean Émile Favre, 422, Imbiribeira. CEP: 51200-060 - Recife/PE - Brasil. E-mail: ana.silva@unifbv.edu.br
} 
exploratory and explanatory perspective. It has a qualitative approach supported by the analysis of seventeen Monitoring Reports, especially the section "evaluation of monitoring experience, regarding to the participation of the students in the condition of monitors. For purposes of data processing, it was chosen to create categories taking into account the dimensions of cognitive, behavioral and emotional student engagement. As results it was possible to evaluate the permanence of the same student continuously by three consecutive supervisions under the guidance of one same teacher; in four of the reports all dimensions of engagement were found. In addition, the cognitive dimension was the most present in the documents analyzed (thirteen), which greatly brings the Institutional Monitoring Program closer to student engagement with a view to a more consistent and meaningful learning of the participating student.

Key words: Tourism; Student engagement; Monitoring program; Experience. 


\section{INTRODUÇÃO ${ }^{1}$}

Os estudos que versam sobre as multipossibilidades de aproximação do aluno a seu aprendizado estão, cada vez mais, sendo analisados enquanto objeto de estudo por pesquisadores da área da educação e correlatas. Nesse sentido o engajamento estudantil, conceito amplamente pesquisado no mundo, vem trazendo aportes ao conhecimento quando avaliado a partir da perspectiva educacional em seus distintos níveis de ensino.

Desse modo e amparando-se nas palavras de Moreira, Moreira e Soares (2018), a universidade é o lócus da formação de um cidadão mais reflexivo, ciente do seu papel na sociedade e protagonista de suas ações. E é justamente nesse espaço que o presente relato de experiências se apresenta. O cenário é focado na Universidade Federal de Pernambuco (Brasil), especificamente nos bacharelados em Hotelaria e em Turismo a partir de uma avaliação quanto à participação de acadêmicos dos dois cursos em questão no Programa de Monitoria Institucional da Universidade. O Programa, de responsabilidade da Pró-Reitoria para Assuntos Acadêmicos (PROACAD), tem por objetivo oportunizar "um espaço de aprendizagem, proporcionado aos alunos dos cursos de graduação, visando o aperfeiçoamento do seu processo de formação e a melhoria da qualidade do ensino" (UFPE, 2018, p. 1).

A escolha em realizar um estudo que alinhasse o engajamento estudantil à monitoria se apoia nos escritos de Coates (2009) especialmente quando se trata a respeito da ideia central do engajamento estudantil: as experiências de aprendizagem incluindo as características acadêmicas ou não, as quais convergem rumo ao aprendizado discente. Ainda nessa construção destaca-se a partilha entre aqueles que fazem parte do sistema que converge ao engajamento discente, seja a instituição de ensino, seus professores e seus funcionários, até mesmo a própria cultura da organização (MARTINS; RIBEIRO, 2017) tem seu papel frente aos resultados em prol do engajamento.

Dessa feita, o presente relato de experiências tem por objetivo avaliar a monitoria acadêmica desenvolvida pelos estudantes dos cursos de Bacharelado em Hotelaria e em Turismo da UFPE, no período de 2013.1 a 2018.1, a partir do engajamento de seus participantes. Para o alcance do objetivo citado foram realizadas

\footnotetext{
${ }^{1}$ Artigo revisado e ampliado. Foi originalmente apresentando no XVI Congresso Internacional de Tecnologia na Educação, 2018.
} 
avaliações, através de critérios previamente estabelecidos, a partir de um instrumento institucional denominado "Relatório de Monitoria". A análise é específica a um grupo de orientandos no período citado que tiveram a supervisão de suas atividades desempenhada por uma das docentes autoras desse relato.

Assim sendo, o problema de pesquisa que abarca o objetivo geral é: como a monitoria acadêmica desenvolvida pelos estudantes dos cursos de Bacharelado em Hotelaria e em Turismo da UFPE, no período de 2013.1 a 2018.1, proporcionou o engajamento estudantil de seus participantes? Ainda sobre a questão-chave do estudo, há de se considerar que distintos elementos podem servir ao engajamento do acadêmico à instituição na qual se vincula, condição essa considerada neste relato, e, por isso, o debruçamento sobre tais aspectos serve para que as instituições possam, cada vez mais, perceber quais indicadores são aqueles que mais trazem envolvimento do estudante para com seu curso e seu espaço acadêmico (NSSE, 2018; AUSSE, 2018).

Como apontado por Pulita (2014, p. 684) "múltiplas inteligências, estilos de aprendizagem e inter, pluri e transdisciplinaridade são exemplos de como a preocupação com a educação ultrapassa a questão da escola em si e impacta em toda estrutura social". E o engajamento estudantil propõe-se a avaliar de que modo as estruturas ofertadas pelas instituições de ensino convergem para a entrega ao mundo do trabalho de profissionais reflexivos, ativos e cientes de seu papel enquanto profissionais, nesse caso hoteleiros e turismólogos. Também não se pode deixar de ressaltar as perspectivas sociais e humanísticas relacionadas ao tema de discussão. Afinal, tratam-se de indivíduos em constante (re) construção de suas habilidades e competências.

Por isso justificam-se enquanto motivações envoltas ao tema a ser debatido as contribuições oriundas do estudo sobre a perspectiva do engajamento estudantil a partir dos resultados de programas de monitoria, haja vista a sua forte relação com a aprendizagem discente e os seus desdobramentos. Sobre tal ação destaca-se a forte adesão do corpo docente e discente do Departamento de Hotelaria e Turismo ao Programa Institucional de Monitoria da instituição de ensino apresentada provendo aos interessados, a partir das diretrizes originárias da PROACAD, editais semestrais de oferta de vagas aos monitores. Portanto, pesquisas que versem sobre boas práticas no ambiente acadêmico e como essas podem ser significativas àqueles que fazem parte desse devem ser estimuladas haja vista ser um tema profícuo de discussões. Registra-se 
ainda como desdobramentos do estudo a aproximação da educação à hotelaria e ao turismo integrando sujeitos e investigando de maneira mais aprofundada os elementos que venham a nortear uma aprendizagem com sentido para àqueles que dela se valem.

\section{NOTAS SUCINTAS SOBRE O ENGAJAMENTO ESTUDANTIL: A APROXIMAÇÃO DO ESTUDANTE A SEU ESPAÇO DE ESTUDO}

A temática engajamento estudantil vem sendo abordada ao longo dos anos sob diferentes perspectivas à luz de distintas áreas do conhecimento. Independentemente do viés dado às pesquisas empreendidas é certo que seus aportes recairão sobre as questões da aprendizagem.

Martins e Ribeiro (2017) apresentam ainda sobre o engajamento as diferentes terminologias que se relacionam ao conceito fim seja ele "envolvimento", "engajamento acadêmico" ou ainda "participação ativa". Para os autores citados, amparando-se nos escritos de Pike e Kuh (2005), independentemente da nomenclatura empregada ao tratar sobre o engajamento do estudante, há de se levar em consideração que o aprendizado do estudante é fruto de uma construção no decorrer de sua vida, ou seja, a ideia da experiência se faz presente e o grau maior ou menor do engajamento está diretamente atrelado a essas experiências. Sobre experiência e construção há de se considerar a estreita aproximação do conceito engajamento estudantil às discussões sobre $\mathrm{o}$ Construtivismo embasadas em teóricos como Dewey, Piaget e Vygotsky, conforme preconiza Wardlow (2004) bem como a aprendizagem baseada na experiência (KOLB, 1984).

Para fins deste estudo acreditou-se na ideia de que o engajamento do estudante teria relação direta com o meio no qual o acadêmico convive e "essa é a base para se esperar que alterações no contexto de ensino e nos ambientes de aprendizagem, promovam alterações nas diversas facetas do engajamento dos estudantes". (BORGES; JÚLIO; COELHO, 2005, p. 2). Há de se considerar também a própria maleabilidade relativa ao engajamento, pois as alterações no contexto no qual se insere o aluno poderão sobremaneira influenciar o seu grau de envolvimento frente a atividade proposta (FREDRICKS; BLUMENFELD; PARIS, 2004). 
Coates, em 2009, apresenta o engajamento estudantil sobre a perspectiva da promoção de condições no contexto acadêmico capazes de gerar uma aprendizagem de alta qualidade. Destaca ainda o papel das instituições de ensino e do seu corpo de funcionários para a geração de conjunturas propícias ao estímulo e que incentivem o envolvimento do acadêmico. Nesse sentido há de considerar que a aprendizagem não se constrói apenas em sala de aula, mais ainda, é no espaço universitário, locus de pesquisa deste estudo e em seus variados programas e projetos, que os discentes podem aderir à iniciação científica, à monitoria, aos estágios e intercâmbios e assim participar de ambientes estimuladores ao seu engajamento.

Partindo da perspectiva de que a temática engajamento estudantil vem sendo frequentemente estudada, autores como Schlecty (1994) buscaram caracterizá-lo a partir de três questões norteadoras, a saber: a) o interesse do aluno pelo desenvolvimento à atividade proposta, b) a persistência do aluno em concluir o que foi proposto apesar dos desafios intrínsecos ao exercício e c) a satisfação pela conclusão da tarefa.

Dada a condição de observância do engajamento sobre diversos prismas, ou multidimensões, autores como Fredricks, Blumenfeld e Paris (2004) e Skinner, Kindermann e Furrer (2009) o apresentam sob três perspectivas: o engajamento e sua relação ao viés cognitivo, ao viés comportamental e ao viés emotivo. Importante destacar que as dimensões do engajamento podem ser percebidas tanto individualmente ou coletivamente, a partir da avaliação do grau de envolvimento do discente em relação à tarefa desempenhada. Em linhas gerais, o engajamento cognitivo relaciona-se ao empenho despendido pelo estudante em prol da compreensão em níveis mais elevados de um determinado assunto. Compreende o esforço e a persistência em prol da conclusão da tarefa solicitada. (BORGES; JÚLIO; COELHO, 2005). O engajamento comportamental possui relação com a participação do acadêmico, seu envolvimento, para com as atividades acadêmicas (FREDRICKS; BLUMENFELD; PARIS, 2004). Já o engajamento emocional é avaliado sob a perspectiva afetiva do estudante para com seus colegas, seus professores, seu espaço escolar e o que o compõe. Some-se a esses fatores o envolvimento do discente frente às suas atividades acadêmicas cotidianas. A própria identificação do acadêmico a seu contexto acadêmico relaciona-se à dimensão emocional do engajamento. 
Há de se considerar ainda os contributos oriundos de estudos sobre o engajamento estudantil desenvolvidos por Instituições que buscam retratar o grau de engajamento dos estudantes nos casos analisados (em níveis de graduação e pósgraduação) para com suas instituições. São exemplos de instrumentos avaliativos: o National Survey of Student Engagement, Australasian Survey of Student Engagement e South African Survey of Student Engagement (NATIONAL SURVEY OF STUDENT ENGAGEMENT, 2018; AUSTRALASIAN SURVEY OF STUDENT ENGAGEMENT, 2018; SOUTH AFRICAN SURVEY OF STUDENT ENGAGEMENT, 2018). Importante ressaltar que no Brasil, de acordo com Martins e Ribeiro (2017) ainda não estão disponíveis instrumentos avaliativos da conceituação e dos desdobramentos envoltos ao engajamento estudantil.

Face à apresentação de uma contextualização sucinta dos estudos relacionados aos conceitos do engajamento estudantil, nas seções a seguir se retratarão a aplicabilidade do tema central dessa pesquisa a partir do caso avaliado e as suas repercussões em prol do envolvimento discente no espaço acadêmico.

\section{PROCEDIMENTOS METODOLÓGICOS}

Os procedimentos metodológicos aplicáveis ao estudo em tela, do tipo relato de experiências, foram delimitados de modo a responder ao problema de pesquisa: como a monitoria acadêmica desenvolvida pelos estudantes dos cursos de Bacharelado em Hotelaria e em Turismo da UFPE, no período de 2013.1 a 2018.1, proporcionou o engajamento estudantil de seus participantes? Nesse sentido, quanto aos objetivos, classifica-se esse relato de experiência a partir da perspectiva exploratória e explicativa, uma vez que será a partir da compreensão e explicação dos fatos relacionados ao caso estudado que se apresentarão as relações entre as categorias avaliadas, podendo esclarecer questões de relevância à pesquisa (GIL, 1999; OMT, 2005).

Quanto aos procedimentos de coleta, é uma pesquisa de abordagem qualitativa amparada nas análises dos relatórios de monitoria, 17 no total, relativos à participação dos discentes na condição de monitores entre os anos de 2013 até o primeiro semestre de 2018. Justifica-se tal marco temporal devido ao primeiro oferecimento de vagas para 
a monitoria por parte de uma das docentes autora do estudo e que continuou a ofertar as oportunidades de atuação ao público estudantil. O documento analisado, criado pela PROACAD, através da Diretoria de Gestão Acadêmica (DGA), Coordenação de Apoio Acadêmico, é padronizado para toda a Instituição e possui entrega obrigatória para o docente orientador e discentes monitores (na condição de bolsistas ou voluntários), ao final de cada semestre letivo. Tem por objetivo apresentar o percurso acadêmico vivenciado pelos pares no decorrer da monitoria, a partir de seções específicas que devem ser redigidas (com espaços destinados ao preenchimento do professor orientador e do seu monitor ou monitora).

Dentre os itens constantes no documento e envoltos à análise dos dados, esta se debruça em especial à seção "avaliação da experiência de monitoria", pois, é nesse espaço que o acadêmico disserta sobre suas impressões, resultados, análise da experiência da monitoria e sua relevância a seu currículo acadêmico. Além da avaliação dos relatórios de monitoria, para fins de compreensão do fato estudado, foram utilizados referenciais bibliográficos que tratassem do tema "engajamento estudantil", tanto na literatura estrangeira como brasileira.

É mister destacar que dada a amplitude do Programa Institucional de Monitoria no Departamento ao qual os cursos de Hotelaria e Turismo encontravam-se vinculados, optou-se por uma amostra aleatória por conveniência para análise, ou seja, a de discentes monitores participantes de disciplinas sob a orientação de uma mesma docente. Para fins de apreciação dos resultados coletados e a garantia do anonimato aos participantes, foram utilizadas as expressões "PE" (perfil do estudante) somado à numeração 1 a 17, já que esse foi o quantitativo de relatórios avaliados.

Relativo ao tratamento dos dados, optou-se pela criação de categorias levando-se em consideração as dimensões do engajamento estudantil apresentadas por Fredricks, Blumenfeld e Paris (2004) e Skinner, Kindermann e Furrer (2009). O período destinado à apuração dos dados foi o mês de julho de 2018. Elegeu-se, como etapa final relativa à análise dos dados, a sua triangulação, conforme preconiza Bryman (2015). Assim, a observância e a avaliação do objeto sob diversas fontes tornaram-se de extrema valia para o atendimento do problema de pesquisa delimitado. 


\section{RESULTADOS}

Como forma de compreender o cenário avaliado no presente relato, a criação de tabelas serviu como uma das técnicas de coleta e posterior análise de modo a apresentar ao leitor questões envoltas ao problema de pesquisa. Assim demonstra-se na tabela 1 as disciplinas as quais tiveram oferta de vagas para monitores e o quantitativo de participantes de 2013.1 a 2018.1.

TABELA 1 - DISCIPLINAS POR SEMESTRE X MONITORES

\begin{tabular}{|c|c|c|c|c|}
\hline Semestre & Curso & Disciplina & $\begin{array}{l}\text { Semestre } \\
\text { letivo }\end{array}$ & $\begin{array}{l}\text { Quantidade de } \\
\text { monitores }\end{array}$ \\
\hline 2013.1 & Turismo & $\begin{array}{l}\text { Teoria Geral do Turismo (TGT) } \\
1\end{array}$ & $1^{\circ}$ & 2 \\
\hline 2013.2 & Turismo & $\begin{array}{l}\text { Ética e Responsabilidade } \\
\text { Socioambiental (ERS) }\end{array}$ & $3^{\circ}$ & 1 \\
\hline 2014.1 & Turismo & $\begin{array}{l}\text { Turismo e Lazer (TL) } \\
\text { Ética e Responsabilidade } \\
\text { Socioambiental (ERS) }\end{array}$ & $\begin{array}{l}3^{\circ} \\
3^{\circ}\end{array}$ & 1 \\
\hline 2014.2 & Turismo & $\begin{array}{l}\text { Turismo e Lazer (TL) } \\
\text { Planejamento e Organização do } \\
\text { Lazer (POL) }\end{array}$ & $\begin{array}{l}3^{\circ} \\
4^{\circ}\end{array}$ & $\begin{array}{l}1 \\
1\end{array}$ \\
\hline 2015.1 & Turismo & Administração Hoteleira (AH) & $2^{\circ}$ & 1 \\
\hline 2015.2 & Hotelaria & $\begin{array}{l}\text { Introdução às Atividades } \\
\text { Turísticas e Hoteleiras (IATH) }\end{array}$ & $1^{\mathrm{o}}$ & Não houve inscritos \\
\hline 2016.1 & Hotelaria & $\begin{array}{l}\text { Planejamento e Organização de } \\
\text { Eventos (POE) }\end{array}$ & $6^{\circ}$ & 1 \\
\hline 2016.2 & Hotelaria & $\begin{array}{l}\text { Introdução às Atividades } \\
\text { Turísticas e Hoteleiras (IATH) }\end{array}$ & $1^{\mathrm{o}}$ & 1 \\
\hline 2017.1 & Turismo & Turismo e Lazer (TL) & $3^{\circ}$ & 2 \\
\hline 2017.2 & $\begin{array}{l}\text { Turismo } \\
\text { Hotelaria }\end{array}$ & $\begin{array}{l}\text { Turismo e Lazer (TL) } \\
\text { Fundamentos do Turismo e da } \\
\text { Hotelaria (FTH) }\end{array}$ & $\begin{array}{l}3^{\circ} \\
1^{o}\end{array}$ & $\begin{array}{l}2 \\
2\end{array}$ \\
\hline 2018.1 & Turismo & Turismo e Lazer (TL) & $3^{\circ}$ & 1 \\
\hline
\end{tabular}

FONTE: Pesquisa, 2018.

A respeito da tabela 1 nota-se que a disciplina "Teoria Geral do Turismo 1" teve a participação de dois monitores em 2013.1. Nos semestres seguintes, outros docentes passaram a ser os responsáveis pelo componente curricular continuando com a oferta da monitoria. Do mesmo modo, a disciplina "Ética e Responsabilidade Socioambiental" ofertou vagas para monitoria em dois semestres, recebendo dois acadêmicos no Programa. "Turismo e Lazer" é o componente curricular que mais agregou acadêmicos à monitoria perfazendo um total de sete discentes. "Planejamento e Organização do 
Lazer" contou com a participação de um discente monitor assim como "Administração Hoteleira". Todas as disciplinas antes citadas fazem parte dos componentes curriculares do curso de Turismo.

Referente ao curso de Hotelaria, a oferta com mais participantes foi na disciplina introdutória do curso, com três participações (a nomenclatura de "Introdução às Atividades Turísticas e Hoteleiras", com a aprovação do novo Plano de Curso, além da atualização do componente curricular foi substituída por "Fundamentos da Hotelaria e do Turismo"). Em 2016 a disciplina de "Planejamento e Organização de Eventos" contou com um monitor. Ainda sobre a tabela 1 há de se destacar que apenas no segundo semestre de 2015 é que a vaga para monitoria não foi ocupada.

No Bacharelado em Turismo, no decorrer de todos os semestres nos quais ocorreu oferta de vagas, as mesmas foram preenchidas por acadêmicos interessados em experienciar a dinâmica envolta ao trabalho do monitor em sala de aula. A tabela 2 retrata o quantitativo geral de monitores por disciplina e curso no decorrer dos semestres avaliados.

TABELA 2 - QUANTITATIVO TOTAL DE MONITORES POR DISCIPLINA

\begin{tabular}{clc}
\hline Curso & \multicolumn{1}{c}{ Disciplina } & \multicolumn{1}{c}{$\begin{array}{c}\text { Quantidade de } \\
\text { monitores (total) }\end{array}$} \\
\hline \multirow{2}{*}{ Turismo } & Teoria Geral do Turismo 1 & 2 \\
& Ética e Responsabilidade Socioambiental & 2 \\
& Turismo e Lazer & 7 \\
& Planejamento e Organização do Lazer & 1 \\
& Administração Hoteleira & 1 \\
& Introdução às Atividades Turísticas e Hoteleiras & 1 \\
& Planejamento e Organização de Eventos & 1 \\
& Fundamentos do Turismo e da Hotelaria & 2 \\
\hline
\end{tabular}

FONTE: Pesquisa, 2018.

Ressalta-se que no curso de Turismo a condição de monitores alcançou 13 participações e em Hotelaria quatro. Há de se observar também que alunos já atuantes enquanto monitor em uma disciplina optaram por continuar, em semestres seguintes, junto à docente orientadora em outros componentes curriculares ou até mesmo permanecer na monitoria na mesma disciplina, mediante novo processo seletivo, conforme ilustrado na tabela 3. 
TABELA 3 - PERMANÊNCIA NO PROGRAMA INSTITUCIONAL DE MONITORIA

\begin{tabular}{|c|c|c|c|}
\hline Semestre & Curso & Disciplina & Perfil do estudante \\
\hline \multirow[t]{2}{*}{2013.1} & Turismo & Teoria Geral do Turismo 1 & PE. 1 \\
\hline & & & PE.2 \\
\hline \multirow[t]{3}{*}{2014.1} & Turismo & Turismo e Lazer & PE.1 \\
\hline & & Ética e Responsabilidade Socioambiental & \\
\hline & & & PE.2 \\
\hline \multirow[t]{3}{*}{2014.2} & Turismo & Planejamento e Organização do Lazer & PE.1 \\
\hline & & Turismo e Lazer & \\
\hline & & & PE.4 \\
\hline 2015.1 & Turismo & Administração Hoteleira & PE.4 \\
\hline 2017.1 & Turismo & Turismo e Lazer & PE. 8 \\
\hline 2018.1 & Turismo & Turismo e Lazer & PE. 8 \\
\hline
\end{tabular}

FONTE: Pesquisa, 2018.

Sobre a continuidade na Monitoria, e concordando com o disposto na obra de Coates (2009), o estímulo ao engajamento do estudante para com a sua aprendizagem sofre influências do ambiente que o cerca e as monitorias analisadas neste estudo podem desempenhar um papel expressivo nesse construto da aprendizagem estudantil. No instante em que se coadunam com dois dos objetivos do Programa Institucional de Monitoria - a relação direta ao aprofundamento dos estudos teóricos do discente participante além da sua ampliação, em termos de experiências, no decorrer de sua vivência universitária (UFPE, 2018) - percebe-se a forte influência de projetos os quais tenham o acadêmico como protagonista do seu aprendizado. Destaca-se, por exemplo, o perfil 1 com três participações em monitorias (Teoria Geral do Turismo 1, Turismo e Lazer, Planejamento e Organização do Lazer). Sobre os dois últimos componentes, num primeiro momento, PE.1 desempenhou suas funções na disciplina que introduz os estudos do Lazer, no curso de Turismo e, em seguida, permaneceu em suas funções, na disciplina "Planejamento e Organização do Lazer", que tem a perspectiva de solidificar os conhecimentos antes tratados, trazendo uma perspectiva prática ao componente em estudo. Os perfis 2, 4 e 8 tiveram duas participações em monitorias.

Após a contextualização do cenário a ser avaliado em termos de cursos, disciplinas e participantes, a análise dos resultados centrou-se nos relatórios de monitoria e em sua seção "avaliação da experiência de monitoria". Tal item, de redação exclusiva do aluno, serve aos professores orientadores como uma espécie de "termômetro", em que é possível perceber o engajamento do discente para com o componente curricular experenciado enquanto monitor. Nesse sentido, foram elencadas categorias de análise criadas à luz dos escritos de Fredricks, Blumenfeld e Paris (2004) 
e Skinner, Kindermann e Furrer (2009) e a perspectiva de dimensões do engajamento sendo essas a emotiva, a cognitiva e a comportamental. A tabela 4 apresenta as dimensões do engajamento encontradas à luz do caso em questão.

TABELA 4 - DIMENSÕES DO ENGAJAMENTO NA PERSPECTIVA DO MONITOR

\begin{tabular}{|c|c|c|c|}
\hline Semestre & Disciplina & Perfil & $\begin{array}{l}\begin{array}{l}\text { Dimensões do engajamento presentes na avaliação da } \\
\text { experiência de monitoria }\end{array} \\
\end{array}$ \\
\hline 2013.1 & TGT 1 & PE.1 & Comportamental e emotiva \\
\hline 2013.1 & TGT 1 & PE. 2 & Cognitiva e comportamental \\
\hline 2013.2 & ERS & PE.3 & Cognitiva e comportamental \\
\hline 2014.1 & TL & PE.1 & Cognitiva e emotiva \\
\hline 2014.1 & ERS & PE. 2 & Cognitiva \\
\hline 2014.2 & TL & PE.4 & Cognitiva \\
\hline 2014.2 & POL & PE.1 & Cognitiva e emotiva \\
\hline 2015.1 & $\mathrm{AH}$ & PE.4 & Cognitiva \\
\hline 2016.1 & POE & PE. 5 & Comportamental e emotiva \\
\hline 2016.2 & IATH & PE.6 & Cognitiva, emotiva e comportamental \\
\hline 2017.1 & $\mathrm{TL}$ & PE.7 & Cognitiva e comportamental \\
\hline 2017.1 & TL & PE. 8 & Cognitiva, emotiva e comportamental \\
\hline 2017.2 & FTH & PE.9 & Cognitiva e emotiva \\
\hline 2017.2 & FTH & PE.10 & Cognitiva \\
\hline 2017.2 & TL & PE.11 & Cognitiva, emotiva e comportamental \\
\hline 2017.2 & TL & PE.12 & Emotiva \\
\hline 2018.1 & TL & PE. 8 & Cognitiva, emotiva e comportamental \\
\hline
\end{tabular}

FONTE: Pesquisa, 2018.

Com a avaliação dos escritos nos relatórios de monitoria em seção destinada à contemplação das impressões dos discentes monitores é de suma importância registrar que em todos os relatórios pelo menos uma das dimensões do engajamento pôde ser encontrada. Cumpre ressaltar sobre os 17 documentos avaliados o enquadramento de nove deles sobre a perspectiva emotiva combinada ou não a outras dimensões, 10 relacionando-se à comportamental também sendo combinada ou não a uma outra dimensão e 13 tratando do engajamento cognitivo em conjunto ou não com os outros tipos.

Fredricks, Blumenfeld e Paris (2004) preconizam sobre o engajamento cognitivo substancialmente a questão do "investimento psicológico" com vistas ao aprendizado e a monitoria aproxima-se dessa situação no instante em que o estudante, no papel de monitor, necessita revisitar os conteúdos programáticos antes estudados sob um novo olhar: o de ser sujeito facilitador junto a seu professor orientador (UFPE, 2018) para seus colegas. Sobre tal questão e as novas possibilidades de experenciar o conteúdo 
programático, PE.2 discorre: "Houve interesse em aprofundar o conhecimento sobre a disciplina e desenvolver habilidades para o futuro exercício da docência”.

Ainda sobre a dimensão cognitiva o PE.7 registrou em sua avaliação: "Aprofundei meus conhecimentos através de leituras de livros e releituras de textos, pude aprender através de debates em grupo com os alunos e professora orientadora e eu, como monitora, tive um olhar crítico nesses debates". Percebeu-se que a dimensão cognitiva é acentuada na experiência da monitoria pelo valor dado à aprendizagem pelos participantes. A revisão dos conteúdos antes estudados e a relevância dada ao conhecimento, agora sob a condição de monitor, influencia sobremaneira na autonomia do sujeito discente no decorrer do seu curso. Condições essas encontradas nas análises empreendidas. Há de se destacar também que parte dos discentes monitores seguiu com seus estudos focados nas áreas nas quais foram monitores repercutindo em Trabalhos de Conclusão de Curso, escrita de artigos científicos, além da participação em eventos nacionais e internacionais.

Concernente à dimensão emocional, os achados se relacionam a aspectos positivos traduzidos por palavras como "satisfação", "apoio", "entusiasmo" por parte dos monitores tanto para com seus colegas, para com a docente orientadora e a disciplina. Sobre a perspectiva da satisfação pessoal PE.8 discorre:

Foi bastante prazeroso rever os mesmos assuntos na perspectiva de segunda monitoria da disciplina, sendo desta vez mais analista com relação à metodologia utilizada pela professora e com o envolvimento da turma, sendo esta do $3^{\circ}$ período. Pude perceber o quanto amadureci criticamente ao longo do curso.

Sobre o engajamento discente para com a disciplina e a docente, PE.9 apresenta:

\begin{abstract}
A escolha, em princípio, pela disciplina foi muito influenciada pela docente e a sua didática. $\mathrm{O}$ modo como fala com os alunos e os ajuda a encontrar a melhor clareza possível sobre todos os assuntos dentro de sala de aula é o que me incentivou a concorrer a vaga de monitoria. Sabia desde o princípio que iria finalizar mais um semestre encantada com o curso que escolhi e com a disciplina "Fundamentos do turismo e da hotelaria" novamente.
\end{abstract}

A perspectiva da dimensão emotiva em relação aos colegas de sala também foi item relatado nas palavras de PE.11: "pude auxiliar colegas quando necessitaram, tentei passar um pouco do que sei e também aprender com eles [...]”. Pôde-se perceber nas 
análises realizadas a satisfação dos discentes monitores por sua atuação e envolvimento ao componente curricular ao sentirem pertencentes e partícipes da construção da disciplina e por que não dizer uma (re) construção pessoal também.

A última dimensão retratada, a comportamental, trata da participação e do envolvimento do discente nas atividades propostas no âmbito escolar e em espaços extraescolares (FREDRICKS; BLUMENFELD; PARIS, 2004). Skinner, Kindermann e Furrer (2009) acrescentam ainda a participação estudantil sob o prisma do esforço, da vontade em desempenhar o que é solicitado, a persistência em cumprir ao que foi solicitado. Sobre tais aspectos PE.8 discorre em sua avaliação:

Diante do aprendizado com os alunos, da relação de confiança com a professora orientadora, foi possível obter um maior amadurecimento social, pessoal e acadêmico, pois as relações que se estabeleceram, as dificuldades compartilhadas e os desafios que surgiram, desempenharam um papel de me preparar para novas experiências dentro de sala de aula e fora dela também.

Outro aspecto relevante dentre os achados da pesquisa tem relação direta com um novo olhar dado pelo estudante sobre seu comportamento, sendo a experiência da monitoria precursora, de certo modo, para uma nova postura do acadêmico como relata PE.6:

\begin{abstract}
Acredito que, com relação às dificuldades apresentadas, foi também um ponto muito importante na minha aprendizagem, que é a questão de saber dividir seu tempo. Por vezes eu me encontrava perdida com meus deveres de monitora e com meus deveres de aluna, não sabia administrar de forma eficiente meu tempo, e isso me prejudicou em alguns aspectos, mas também me ensinou muito, e acredito que hoje eu já saiba organizar melhor minhas obrigações.
\end{abstract}

Face ao exposto ressalta-se a estreita ligação entre a realização da monitoria e o engajamento estudantil, haja vista o somatório de elementos que os unem. A proposta de ambientes acadêmicos propícios ao protagonismo do estudante tem, por exemplo, na monitoria, campo propício para que o acadêmico se perceba enquanto sujeito ativo da sua própria aprendizagem em seu percurso universitário, cabendo às instituições a promoção de ações que venham a incentivar e envolver o público discente. 


\section{CONSIDERAÇÕES FINAIS}

Frente aos resultados apresentados à luz do problema do estudo em questão, ressalta-se que as discussões propostas a partir do entrelaçamento do engajamento dos estudantes participantes do Programa Institucional de Monitoria da UFPE e pertencentes aos cursos de Bacharelado em Hotelaria e em Turismo, cumpriram os seus propósitos. Amparados por teóricos que vem desenvolvendo pesquisas sobre o engajamento discente no cenário do ensino superior, a opção em relacionar monitoria às multidimensões comportamental, cognitiva e emotiva (FREDRICKS; BLUMENFELD; PARIS, 2004; SKINNER; KINDERMANN; FURRER, 2009) do engajamento se fizeram presentes nesse relato. Num primeiro momento, o estudo apresentou o cenário no qual a análise ocorreu.

A partir da distribuição das disciplinas, as quais receberam monitores no decorrer dos anos de 2013 e 2018 (primeiro semestre), bem como o quantitativo de participantes e a adesão em mais de uma monitoria por parte dos discentes, foram tratadas as questões com vistas a estabelecer as possíveis relações entre os acadêmicos participantes e o seu envolvimento não somente ao componente curricular no qual encontrava-se na condição de monitor mas também a sua avaliação da experiência. Foi possível examinar a permanência de um mesmo estudante, por exemplo, em três monitorias distintas sob orientação de um mesmo docente, bem como a aproximação do discente à área do conhecimento correlata à monitoria repercutindo em produções de trabalhos de conclusão de curso e artigos científicos apresentados em congressos.

Com a segunda etapa de análises, debruçada sobre os relatórios de monitoria, seção avaliação da experiência de monitoria, foi possível, a partir da leitura, a percepção das dimensões do engajamento e sua presença em 17 documentos analisados. Destacase que em todos os relatórios avaliados, pelo menos uma das dimensões cognitiva, comportamental e emotiva se fez presente. Em quatro dos relatórios, as três dimensões foram percebidas a partir dos escritos dos discentes monitores. Ademais, a dimensão cognitiva foi a mais presente nos documentos analisados estando destacada em 13 relatórios, o que sobremaneira destacou o Programa Institucional de Monitoria da IES analisado para um aprendizado mais consistente do discente participante da ação uma 
vez que, o revisitar dos conteúdos programáticos antes vivenciados, esses puderam ser internalizados a partir de novos significados, haja vista uma releitura desses.

Sobre a dimensão comportamental, presente em 10 relatórios analisados, a atuação positiva dos monitores frente às situações experenciadas em sala de aula apresentou, nos relatos, possiblidades quanto a mudanças de comportamento, que, de certo modo, prejudicavam o discente, como um melhor uso do seu tempo para com as atribuições do cotidiano; o tempo para a aula e o tempo para a monitoria passaram a ser entendidos.

Por fim, a dimensão emocional esteve destacada em nove relatórios analisados, apresentando as relações entre os pares, para com a disciplina e a docente orientadora enfatizando quão importante é o estabelecimento de um ambiente sadio e estimulador ao protagonismo do discente.

Para as autoras do estudo a promoção da monitoria pela instituição estudada cumpre com seu papel na medida em que através do seu Programa Institucional se estabelece "Ampliar a participação do aluno de graduação na vida acadêmica, mediante a realização de atividades relacionadas ao ensino". (2018, p.1). Sentir-se partícipe e responsável pelo bom andamento do componente curricular mediado pelo professor orientador deve ser uma das premissas chave de ações, com vistas ao envolvimento do discente em seu espaço acadêmico e, nesse sentido, a monitoria poderá ser um meio transformador com vistas a uma aprendizagem e sua visitação e retorno àqueles que dela fazem parte.

\section{REFERÊNCIAS}

AUSTRALASIAN SURVEY OF STUDENT ENGAGEMENT. AUSSE. Findings from the AUSSE. Disponível em: <https://www.acer.org/ausse/findings-from-theausse>. Acesso em: 27/07/2018.

BORGES, O.; JÚLIO, J. M.; COELHO, G. R. Efeitos de um ambiente de aprendizagem sobre o engajamento comportamental, o engajamento cognitivo e sobre a aprendizagem. In: V ENCONTRO NACIONAL DE PESQUISA EM EDUCAÇÃO EM CIÊNCIAS. Atas do V ENPEC, 2005.

BRYMAN, A. Social research methods. Oxford: Oxford University Press, 2015. 
COATES, H. B. Engaging students for success. Australia: Australian Council for Educational Research, 2009.

FREDRICKS, J. A.; BLUMENFELD, P. C.; PARIS, A. H. School engagement: potential of the concept, state of the evidence. Review of Educational Research, Pittsburgh, v. 74, n. 1, p. 59-109, 2004.

GIL, A. C. Métodos e técnicas de pesquisa social. 5. ed. São Paulo: Atlas, 1999.

KOLB, D. Experiential Learning: experience as the source of learning and development. New Jearsey: Prentice Hall, 1984. cap. 2, p. 20 -38.

MARTINS, L. M. de; RIBEIRO, J. L. D. Engajamento do estudante no ensino superior como indicador de avaliação. Avaliação: Campinas; Sorocaba, v. 22, n. 1, p. 223-247, mar. 2017.

MOREIRA, L. K. R.; MOREIRA, L. R.; SOARES, M. G. Educação superior no Brasil: discussões e reflexões. Educação por escrito: Porto Alegre, v. 9, n. 1, p. 134-150, jan.jun. 2018.

NATIONAL SURVEY OF STUDENT ENGAGEMENT. NSSE. About NSSE. Disponível em: <http://nsse.indiana.edu/html/about.cfm>. Acesso em: 27/07/2018.

ORGANIZAÇÃO MUNDIAL DO TURISMO. Introdução à metodologia da pesquisa em Turismo. São Paulo: Rocca, 2005.

PULITA, E. J. A experiência e o flanar como categorias críticas na reflexão das interfaces entre Turismo e Educação. Turismo e Sociedade: Curitiba, v. 7, n. 4, p. 673693, out. 2014.

SCHLETCY, P. Increasing Student Engagement. Jefferson City: Missouri Leadership Academy, 1994.

SKINNER, E. A.; KINDERMANN, T.; FURRER, C. A motivational perspective on engagement and disaffection: conceptualization and assessment of children's behavioral and emotional participation in academic activities in the classroom. Educational and Psychological Measurement, v. 69, p. 493-525, 2009.

SOUTH AFRICAN SURVEY OF STUDENT ENGAGEMENT. Focusing the Student Experience on Success through Student Engagement. Disponível em: <http://www.che.ac.za/media_and_publications/other-stakeholder-s-publications/southafrican-survey-student-engagement>. Acesso em: 03/08/2018.

UNIVERSIDADE FEDERAL DE PERNAMBUCO. Edital n⿳06/2017. Programa Institucional de Monitoria 2018.1. Recife: [s.n.]. Disponível em: <https://www.ufpe.br/documents/38970/1112895/Edital+06-

2017+Monitoria+2018.pdf/434b7c32-d279-4942-b8a5-159fd1a50fa5>. Acesso em: 30/07/2018. 
WARDLOW, L. Teaching in a Digital Age. Disponível em: $<$ https://www.pearsoned.com/wp content/uploads/DigitalAge_EngagementScience_042914.pdf $>$ Acesso em: 03/07/2018.

Recebido em: 26-11-2018.

Aprovado em: 26-12-2018.

Versão finalizada para publicação em: 14-02-2019. 